\title{
TESTOWANIE PRZYCZYNOWOŚCI POMIĘDZY KRÓTKOTERMINOWYMI STOPAMI PROCENTOWYMI W POLSCE, USA I STREFIE EURO
}

\begin{abstract}
$\mathrm{Z}$ a r y s t r e ś c i. W artykule podjęto próbę zbadania przyczynowości w sensie Grangera dla jedno-, trzy- i sześciomiesięcznych stóp procentowych Polski, USA i strefy euro. Wykorzystano metodę Toda-Yamamoto, pozwalającą badać przyczynowość dla szeregów skointegrowanych. $\mathrm{W}$ badaniach integracji i kointegracji zmiennych zastosowano rozszerzony test Dickey'a-Fullera i test Phillipsa-Perrona oraz metodę Johansena. Uzyskane wyniki sugerują, że polski rynek stóp procentowych wykazuje długookresowy związek z rynkiem strefy euro; nie stwierdzono natomiast zależności przyczynowej od rynku USA.
\end{abstract}

S ło w a k l u c z o w e: stopy procentowe, przyczynowość, Polska, USA, strefa euro.

\section{WSTĘP}

Międzynarodowe powiązania stóp procentowych od dawna stanowią przedmiot zainteresowania ekonomistów. Teoria parytetu stóp procentowych pozwala na wysunięcie wniosku, że przy założeniu doskonałej mobilności kapitału oraz stałych kursów walutowych, realne stopy procentowe różnych krajów będą równe. W rzeczywistości faktyczne stopy procentowe na poszczególnych rynkach krajowych nie są identyczne, choć szereg analiz wskazuje, że liberalizacja rynków finansowych i ich coraz silniejsza integracja powodują spadek dysproporcji w poziomie krajowych stóp procentowych. Badania oceny stopnia integracji pomiędzy różnymi rynkami finansowymi rozpoczęły się już we wczesnych latach 80-tych. Wraz z rozwojem bardziej zaawansowanych technik ekonometrycznych, takich jak testy stacjonarności i kointegracji, zaczęły powstawać opracowania o długookresowych relacjach między stopami procentowymi różnych krajów. Badania były prowadzone zarówno dla realnych jak i nominalnych stóp procentowych. Przedmiotem prowadzonych analiz najczęściej były związki między stopami procentowymi strefy euro a amerykańskimi, oraz po- 
między tymi stopami a innymi krajowymi stopami procentowymi. Uzyskiwane wyniki nie były przy tym jednoznaczne. Przykładowo brak kointegracji w swojej pracy wykazali Mills i Mills (1991), porównując dzienne notowania stóp procentowych oparte na pięcioletnich obligacjach rządowych dla czterech rynków: USA, UK, Niemiec i Japonii, w latach 1986-1989. Powiązania długookresowe znaleźli natomiast m.in. Bremnes, Gjerde i Saettem (1997) analizując trzymiesięczne stopy procentowe USA, UK, Niemiec, Francji i Japonii w latach 1984-1994. Ci sami autorzy w 2001 r. stwierdzili istnienie kointegracji dla trzymiesięcznych i dziesięcioletnich stóp procentowych na rynkach USA, Niemiec i Norwegii w latach 1990-1997 i wiodącą rolę stóp rynku amerykańskiego dla poziomu stóp na pozostałych rynkach. Yang, Shim i Khan (2007) znaleźli długookresowe powiązania między trzymiesięcznymi stopami procentowymi USA i strefy euro w latach 1993-2002 oraz wykazali wzajemną przyczynowość w sensie Grangera między nimi. Relatywnie mało analiz przeprowadzonych zostało dla krajów o słabiej rozwiniętych rynkach finansowych, w tym dla Polski.

Podstawowym celem niniejszej pracy było zbadanie, czy pomiędzy krótkoterminowymi stopami procentowymi Polski, USA i strefy euro zachodzą długookresowe związki oraz jaki kierunek mają ewentualne zależności pomiędzy poszczególnymi rynkami. Starano się również określić, czy istnieją różnice w powiązaniach stóp krajowych z zagranicznymi w zależności od terminu realizacji. W tym celu analizy przeprowadzono dla jedno-, trzy- i sześciomiesięcznych stóp procentowych.

Do testowania przyczynowości wykorzystano procedurę opracowaną przez Toda i Yamamoto (1995), której zaletą jest możliwość badania przyczynowości w sensie Grangera dla szeregów zintegrowanych.

\section{METODOLOGIA}

Zgodnie $\mathrm{z}$ ogólną procedura, przed badaniem przyczynowości $\mathrm{w}$ sensie Grangera metodą Toda-Yamamoto, przeprowadzono testowanie zmiennych w kierunku integracji i kointegracji.

Do badania stopnia integracji zmiennych zastosowano rozszerzony test Dickey'a-Fullera (ADF) oraz test Phillipsa-Perrona (PP). Do badania kointegracji wykorzystano metodę Johansena ze statystykami śladu i wartości maksymalnej. Przed zastosowaniem każdej metody badania kointegracji, należy dokonać wyboru opóźnień. W pracy skorzystano z trzech standardowych kryteriów, zamieszczanych w pakietach komputerowych: Akaike (AIC), Schwarza-Bayesa (SC) i Hannan-Quinna (HQ).

Definicję przyczynowości w sensie Grangera (Granger 1969) można krótko sformułować w następujący sposób: ,jeżeli zmienna $X$ jest przyczyną w sensie Grangera zmiennej $Y$, to średni błąd kwadratowy prognozy $Y$ (MSE) opartej na 
przeszłych wartościach obu zmiennych, jest mniejszy niż błąd prognozy opartej na przeszłych wartościach samej tylko zmiennej $Y^{\prime}$.

Klasyczny test nie-przyczynowości Grangera jest przeprowadzany poprzez badanie następującej regresji:

$$
y_{t}=\gamma+\sum_{i=1}^{k} \alpha_{i} y_{t-i}+\sum_{i=1}^{k} \beta_{i} x_{t-i}+\varepsilon_{t}
$$

i testowanie łącznej hipotezy zerowej $H_{0}: \beta_{1}=\beta_{2}=\ldots=\beta_{k}=0$, z wykorzystaniem statystyki Walda.

Zmienna $x$ jest przyczyną zmiennej $y$ w sensie Grangera, jeżeli hipoteza zerowa jest odrzucona. Istotna wartość statystyki testowej wskazuje na to, że zmienna $x$ ma predyktywny wpływ na prognozę zmiennej $y$, niezależnie od informacji zawartej w przeszłości tej ostatniej.

Test ten oparty jest na asymptotycznej teorii i wartości krytyczne są prawidłowe tylko dla stacjonarnych zmiennych (Granger, 1981). W układach skointegrowanych takie testy są bardziej złożone, gdyż istnienie pierwiastków jednostkowych stwarza rozmaite komplikacje we wnioskowaniu statystycznym, por. np. Toda i Phillips (1993) oraz Toda i Yamamoto (1995). Ponieważ wiele zmiennych ekonomicznych, postrzeganych jako proces stochastyczny, zawiera pierwiastki jednostkowe, testowanie nie-przyczynowości Grangera dla zintegrowanych i skointegrowanych szeregów czasowych stało się ważnym tematem współczesnych badań.

Toda i Yamamoto (1995) zaproponowali interesująca, a zarazem prostą procedurę (krótko określaną jako T-Y) wykorzystującą estymację „opóźnionego” modelu VAR, która gwarantuje asymptotyczny rozkład statystyki Walda nawet w przypadku kointegracji zmiennych. Dowiedli oni, że test Walda z restrykcjami parametrów modelu $\operatorname{VAR}(k)$ ma asymptotyczny rozkład $\chi^{2}$, pod warunkiem, że estymowany jest model $\operatorname{VAR}\left(k+d_{\max }\right)$, gdzie $d_{\max }$ jest maksymalnym stopniem integracji zmiennych występujących w modelu.

W przypadku badania przyczynowości zmiennych $x$ i $y$, estymowany jest za pomocą metody najmniejszych kwadratów następujący model VAR dla dwu zmiennych:

$$
\begin{aligned}
& y_{t}=\gamma_{10}+\sum_{i=1}^{k+d} \alpha_{1 i} y_{t-i}+\sum_{i=1}^{k+d} \beta_{1 i} x_{t-i}+\varepsilon_{1 t} \\
& x_{t}=\gamma_{20}+\sum_{i=1}^{k+d} \alpha_{2 i} x_{t-i}+\sum_{i=1}^{k+d} \beta_{2 i} y_{t-i}+\varepsilon_{2 t}
\end{aligned}
$$

gdzie $k$ jest optymalnym rzędem opóźnienia, a $d=d_{\max }$ jest maksymalnym stopniem integracji zmiennych $x$ i $y$. 
Następnie stosuje się test Walda $\mathrm{z}$ narzuconymi restrykcjami zerowymi na parametry wyjściowego modelu $\operatorname{VAR}(\mathrm{k})$ (tak zwany zmodyfikowany test Walda), z hipotezą $H_{0}: \beta_{1 i}=0, i \leq k$ dla pierwszego równania $(, x$ nie jest przyczyną $\left.y^{\prime \prime}\right)$ oraz z hipotezą $H_{0}: \beta_{2 i}=0, i \leq k$ dla drugiego równania (,y nie jest przyczyną $x ")$.

Dodatkowe opóźnienia $\left(d_{\max }\right)$ nie są poddawane restrykcjom. Zgodnie z Toda i Yamamoto, gwarantuje to, że asymptotyczne wartości krytyczne moga być zastosowane, mimo iż testujemy przyczynowość między zintegrowanymi zmiennymi.

Badania przeprowadzone przez Dolado i Lutkepohla (1996) oraz Giles i Mirza (1999) potwierdzają, że mimo prostoty proponowanej metody jest ona efektywna i statystyka Walda nie-przyczynowości Grangera ma asymptotyczny rozkład $\chi^{2}$ w modelu VAR, niezależny od systemowej integracji i kointegracji.

Zapata i Rambaldi (1997) sugerują, że dodatkową zaletą metody T-Y jest to, iż w celu przetestowania przyczynowości Grangera w strukturze VAR, nie jest konieczne wstępne testowanie zmiennych pod względem właściwości integracji i kointegracji (pod warunkiem, że maksymalny rząd integracji nie przekracza długości opóźnienia w modelu VAR). Jednak według Toda i Yamamoto (1995) procedura $\mathrm{T}-\mathrm{Y}$ nie może zastępować konwencjonalnego testowania wstępnego pierwiastków jednostkowych i kointegracji w szeregach czasowych. Badania te powinny być traktowane jako uzupełniające się nawzajem, komplementarne, ale nie substytucyjne.

\section{DANE}

W analizie zostały wykorzystane miesięczne $(1 \mathrm{M})$, trzymiesięczne $(3 \mathrm{M})$ i sześciomiesięczne (6M) stopy procentowe polskie, amerykańskie i strefy euro. Przez większość ekonomistów są one uważane za najbardziej reprezentatywne dla stóp krótkoterminowych. Dane (notowania dzienne) zostały udostępnione przez NBP.

Zakres danych obejmuje okres od 01.01.2003 do 22.07.2008. Koniec badanego przedziału czasowego zdeterminowany został przez posiadany zakres danych, natomiast początek przedziału został ustalony na podstawie analizy wspólnych wykresów. Mniej więcej od początku 2003 roku nastąpiło zbliżenie ścieżki polskich stóp procentowych do stóp USA i strefy euro. Dane zostały dla celów badania przetworzone na dane tygodniowe ${ }^{1}$ (wybrany dzień tygodnia). Liczba obserwacji tygodniowych wynosi 290. Poniżej przedstawione są wykresy zmiennych dla każdego terminu do wykupu z osobna.

\footnotetext{
${ }^{1}$ Wyniki badań autorki w pracy „Wpływ częstotliwości obserwacji na kointegrację krótkoterminowych stóp procentowych w Polsce, USA i strefie euro" (http://ekonometria.wzr.pl/ referaty_09.php), sugerują, że optymalne w tym wypadku będzie użycie danych tygodniowych.
} 


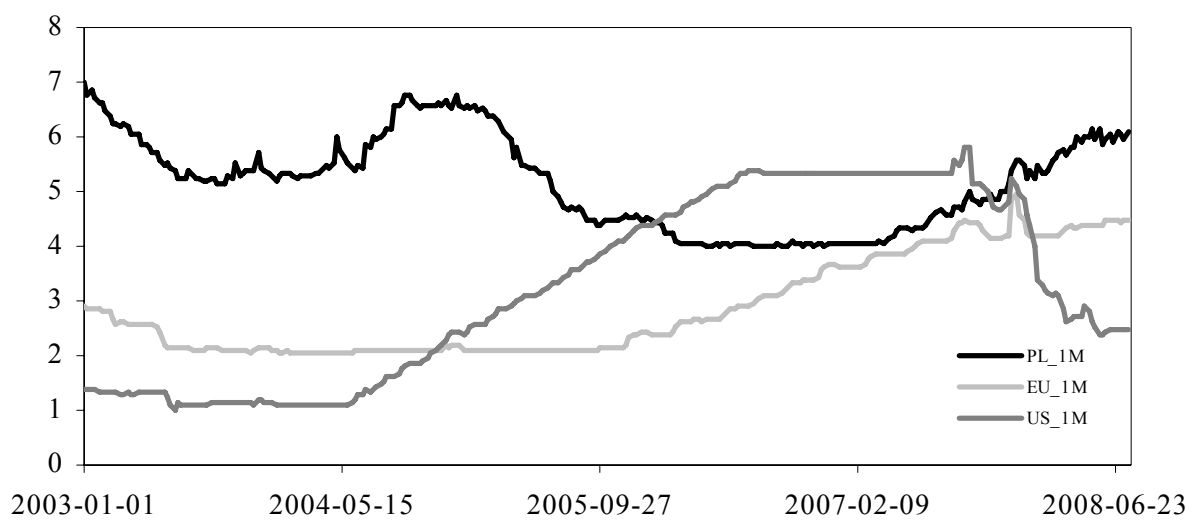

Wykres 1. Jednomiesięczne stopy procentowe Polski, strefy euro i USA

Źródło: opracowanie własne.

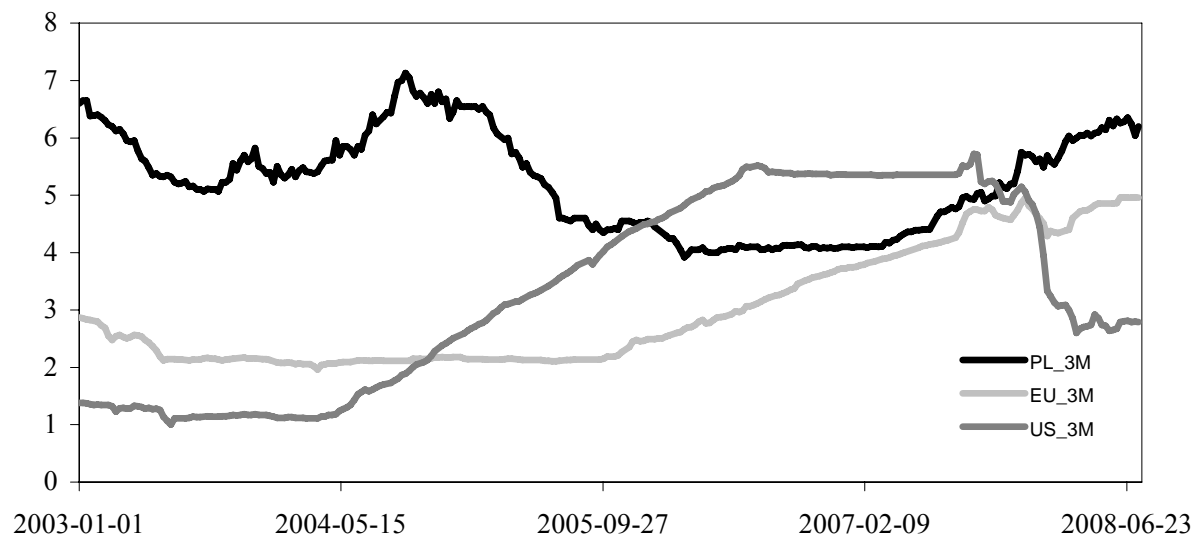

Wykres 2. Trzymiesięczne stopy procentowe Polski, strefy euro i USA

Źródło: opracowanie własne.

\section{WYNIKI EMPIRYCZNE}

Stopień integracji zmiennych zbadano za pomocą rozszerzonego testu Dickeya-Fullera oraz testu Phillipsa-Perrona. Opóźnienia do testu ADF wybrano kierując się kryterium SC, natomiast do testu PP wykorzystano wagi NeweyWest obliczane dla jądra Bartletta. Jako wymagany poziom istotności przyjęto poziom $\alpha=0,05$. Wyniki obu testów jednoznacznie wskazały na to, że wszystkie badane szeregi stóp procentowych są zintegrowane w stopniu pierwszym. ${ }^{2}$

\footnotetext{
${ }^{2} \mathrm{Z}$ uwagi na oszczędność miejsca, nie umieszczono w pracy szczegółowych wyników testów dla poziomów oraz przyrostów zmiennych.
} 


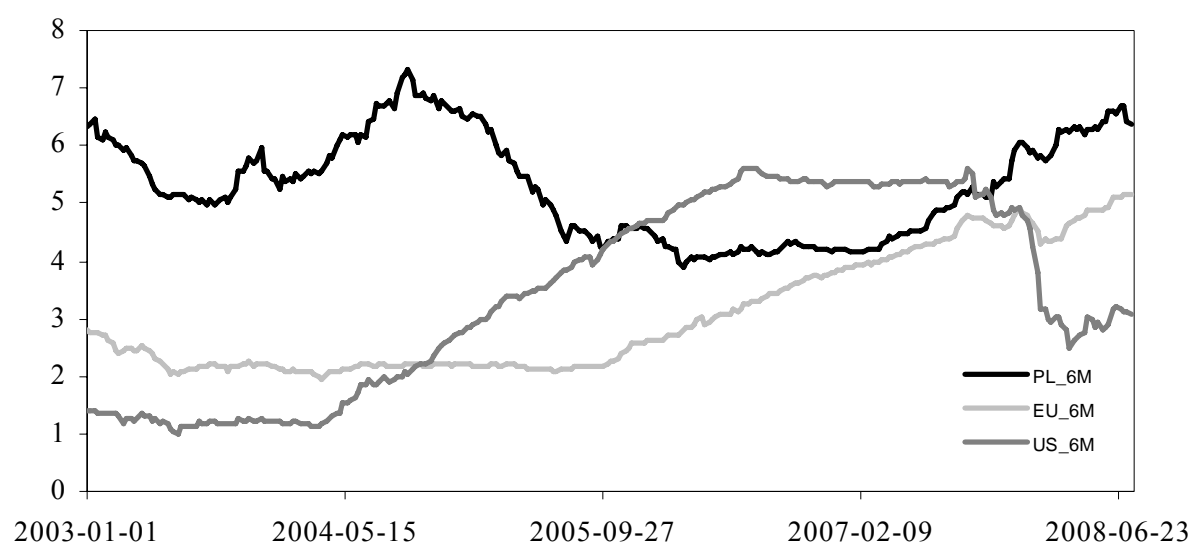

Wykres 3. Sześciomiesięczne stopy procentowe Polski, strefy euro i USA

Źródło: opracowanie własne.

Badanie kointegracji przeprowadzano osobno dla każdej kategorii terminowej. W prowadzonych przez autorkę badaniach została stwierdzona kointegracja między wszystkimi trzema rozpatrywanymi rodzajami stóp procentowych (polskimi, amerykańskimi i strefy euro), zarówno w przypadku stóp jednomiesięcznych, jak i trzy- oraz sześciomiesięcznych. W tym opracowaniu jednak przedmiotem naszego zainteresowania jest kointegracja parami, z uwagi na ewentualne dalsze badanie przyczynowości.

Przed badaniem kointegracji określono liczbę opóźnień dla modelu VAR. W przypadku, gdy analiza ma się koncentrować wyłącznie na stwierdzeniu istnienia wektora lub wektorów kointegrujących, wystarczy dobrać wielkości opóźnienia odpowiednio duże, tak aby wyeliminowały autokorelację składnika losowego z poszczególnych równań. W związku z tym, mimo że kryterium Akaike ma skłonność do zawyżania wartości opóźnień, jako stopień opóźnienia użyty do badania, wybierano maksymalny ze wskazanych przez rozpatrywane tej pracy kryteria. Wyniki doboru opóźnienia (wybieranego z przedziału od 0 do 10) pokazane są w tabeli 1.

$\mathrm{W}$ metodzie Johansena przyjęto opcję testowania $\mathrm{z}$ ograniczonym wyrazem wolnym, ale analogiczne wyniki były uzyskiwane dla opcji z ograniczonym trendem i nieograniczonym wyrazem wolnym. Do testowania kointegracji wykorzystano dwie statystyki: śladu i wartości maksymalnej. Jako wymagany poziom istotności przyjęto poziom $\alpha=0,05$. 
Tabela 1. Dobór opóźnienia dla modelu VAR

\begin{tabular}{|c|c|c|c|}
\hline Model VAR & AIC & SC & HQ \\
\hline PL_1M - EU_1M & $9^{*}$ & 2 & 2 \\
\hline PL_1M - US_1M & $9^{*}$ & 2 & 4 \\
\hline EU_1M - US_1M & $10^{*}$ & 3 & 7 \\
\hline PL_3M - EU_3M & $8^{*}$ & 2 & 6 \\
\hline PL_3M - US_3M & $9^{*}$ & 2 & 3 \\
\hline EU_3M - US_3M & $10^{*}$ & 3 & 2 \\
\hline PL_6M - EU_6M & $4^{*}$ & 2 & 3 \\
\hline PL_6M - US_6M & $7^{*}$ & 2 & $3^{*}$ \\
\hline EU_6M - US_6M & $3^{*}$ & 2 & \\
\hline
\end{tabular}

* Wybrany (maksymalny) stopień opóźnienia.

Źródło: obliczenia własne.

Przykładowe wyniki analizy kointegracji przy użyciu tych statystyk dla modelu dwu zmiennych (PL_1M i EU_1M) przedstawione są w tabeli 2.

Tabela 2. Testowanie kointegracji dla PL_1M i EU_1M

\begin{tabular}{|c|c|c|c|c|}
\hline Hipoteza zerowa & Wartość własna & Statystyka śladu & $\begin{array}{c}\text { Wartość krytyczna } \\
(0,05)\end{array}$ & P-value \\
\hline$r_{0}=0^{*}$ & 0,088226 & 28,65548 & 20,26184 & 0,0027 \\
\hline$r_{0} \leq 1$ & 0,009567 & 2,701342 & 9,164546 & 0,6379 \\
\hline
\end{tabular}

\begin{tabular}{|c|c|c|c|c|}
\hline Hipoteza zerowa & Wartość własna & $\begin{array}{c}\text { Statystyka maks. } \\
\text { wartości }\end{array}$ & $\begin{array}{c}\text { Wartość krytyczna } \\
(0,05)\end{array}$ & P-value \\
\hline$r_{0}=0^{*}$ & 0,088226 & 25,95413 & 15,89210 & 0,0010 \\
\hline$r_{0} \leq 1$ & 0,009567 & 2,701342 & 9,164546 & 0,6379 \\
\hline
\end{tabular}

* Hipoteza odrzucona na poziomie istotności 0,01 ; jeden wektor kointegrujący.

Źródło: opracowanie własne.

Tabela 3. Ogólne wyniki badania kointegracji

\begin{tabular}{|c|c|c|}
\hline \multicolumn{2}{|c|}{ Model } & Liczba wektorów kointegrujących \\
\hline \multirow{3}{*}{$1 M$} & PL-EU & 1 \\
\cline { 2 - 3 } & PL-US & 0 \\
\cline { 2 - 3 } & EU-US & 1 \\
\hline \multirow{3}{*}{$3 M$} & PL-EU & 1 \\
\cline { 2 - 3 } & PL-US & 0 \\
\cline { 2 - 3 } & EU-US & 1 \\
\hline \multirow{3}{*}{$6 M$} & PL-EU & 0 \\
\cline { 2 - 3 } & PL-US & 0 \\
\cline { 2 - 3 } & EU-US & 1 \\
\hline
\end{tabular}

Źródło: opracowanie własne.

Syntetyczne wyniki badania kointegracji parami (dla wszystkich rozpatrywanych zmiennych) przedstawione natomiast są w tabeli 3. Zostały zamiesz- 
czone w niej tylko ostateczne konkluzje co do istnienia i charakteru kointegracji, tj. podana została liczba wektorów kointegrujących.

Jak widać $\mathrm{z}$ wyników umieszczonych $\mathrm{w}$ tabeli, kointegracja ma miejsce między stopami amerykańskimi i strefy euro, dla każdej z badanych terminowości. Stwierdzona została też kointegracja między polskimi stopami procentowymi i stopami strefy euro, w przypadku stóp jedno- oraz trzymiesięcznych. Brak natomiast kointegracji między polskimi stopami procentowymi a amerykańskimi. Wyniki te są uzasadnione m.in. w kontekście stwierdzanego w wielu badaniach spadku powiązania kursu złotego $\mathrm{z}$ dolarem, a wzrostu powiązania $z$ euro.

W przypadku zmiennych, które okazały się skointegrowane, przeprowadzono następnie badanie przyczynowości w sensie Grangera metodą TodaYamamoto, w celu ustalenia kierunku przyczynowości.

Tabela 4. Wyniki badania przyczynowości

\begin{tabular}{|c|c|c|c|c|}
\hline Przyczyna $\rightarrow$ skutek & Test & Wartość & St. swobody & P-value \\
\hline \multirow{2}{*}{ EU_1M $\rightarrow$ PL_1M } & F-statistic & 1,694813 & $(9,259)$ & 0,0904 \\
& Chi-square & 15,25332 & 9 & 0,0842 \\
\hline \multirow{2}{*}{ PL_1M $\rightarrow$ EU_1M } & F-statistic & 0,866365 & $(9,259)$ & 0,5559 \\
& Chi-square & 7,797289 & 9 & 0,5547 \\
\hline \multirow{2}{*}{ EU_1M $\rightarrow$ US_1M } & F-statistic & 5,942929 & $(10,256)$ & 0,0000 \\
& Chi-square & 59,42929 & 10 & 0,0000 \\
\hline \multirow{2}{*}{ US_1M $\rightarrow$ EU_1M } & F-statistic & 1,098849 & $(10,256)$ & 0,3633 \\
& Chi-square & 10,98849 & 10 & 0,3584 \\
\hline \multirow{2}{*}{ EU_3M $\rightarrow$ PL_3M } & F-statistic & 1,958878 & $(8,262)$ & 0,0519 \\
& Chi-square & 15,67102 & 8 & 0,0473 \\
\hline \multirow{2}{*}{ PL_3M $\rightarrow$ EU_3M } & F-statistic & 1,351141 & $(8,262)$ & 0,2185 \\
& Chi-square & 10,80913 & 8 & 0,2128 \\
\hline \multirow{2}{*}{ EU_3M $\rightarrow$ US_3M } & F-statistic & 3,470157 & $(10,256)$ & 0,0003 \\
& Chi-square & 34,70157 & 10 & 0,0001 \\
\hline \multirow{2}{*}{ US_3M $\rightarrow$ EU_3M } & F-statistic & 1,627023 & $(10,256)$ & 0,0991 \\
& Chi-square & 16,27023 & 10 & 0,0922 \\
\hline \multirow{2}{*}{ EU_6M $\rightarrow$ US_6M } & F-statistic & 2,717307 & $(3,277)$ & 0,0450 \\
& Chi-square & 8,151920 & 3 & 0,0430 \\
\hline \multirow{2}{*}{ US_6M $\rightarrow$ EU_6M } & F-statistic & 1,343715 & $(3,277)$ & 0,2605 \\
& Chi-square & 4,031145 & 3 & 0,2581 \\
\hline
\end{tabular}

Źródło: opracowanie własne.

Dla każdej rozpatrywanej pary zmiennych odrębnie estymowano model VAR $(k+d)$, gdzie jako $k$ przyjmowano ustalony wcześniej przy badaniu kointegracji rząd opóźnienia dla danego modelu, natomiast $d$ we wszystkich przy- 
padkach wynosiło 1 (stopień integracji zmiennych). Następnie stosowano test Walda $\mathrm{z}$ nałożonymi restrykcjami zerowymi na pierwsze $k$ parametrów.

Wyniki badania zamieszczone są w tabeli 4 .

Wyniki badania przyczynowości metodą T-Y sugerują, że w przypadku stóp procentowych jedno- $\mathrm{i}$ trzymiesięcznych, stopy procentowe strefy euro są przyczyną w sensie Grangera dla stóp polskich, przy czym ta zależność jest silniejsza w przypadku stóp trzymiesięcznych. Zdecydowanie została wykluczona odwrotna zależność. Otrzymane wyniki są zatem logiczne z punktu widzenia ekonomii; polski rynek stóp procentowych jest bardzo niewielki w porównaniu $\mathrm{z}$ rynkiem strefy euro.

Wyniki badań wskazują także na istnienie zależności przyczynowej między stopami amerykańskimi a stopami strefy euro dla każdego rozpatrywanego terminu do wykupu. Relacja przyczynowości w przypadku stóp jednomiesięcznych i sześciomiesięcznych jest jednokierunkowa - prowadzi od stóp strefy euro do amerykańskich, aczkolwiek z różnym nasileniem. Jedynie w przypadku stóp trzymiesięcznych przyczynowość jest wzajemna, jednak tu także zdecydowanie silniejsza jest relacja przyczynowa w kierunku od stóp strefy euro do amerykańskich, niż odwrotnie. Uzyskane wyniki odbiegają od przeprowadzanych dla wcześniejszych lat badań, por. np. Yang, Shim i Khan (2007). Może to sugerować rosnące znaczenie strefy euro na rynkach finansowych.

\section{PODSUMOWANIE}

Na przestrzeni ostatnich kilkunastu latach polski rynek finansowy przeszed istotne przemiany strukturalne i jakościowe. Jednym z przejawów tych przemian jest rosnąca integracja rynku polskiego z rynkami zagranicznymi. Wynika ona nie tylko z reform gospodarczych, ale i integracji w ramach Unii Europejskiej.

Uzyskane wyniki wskazują, że polski rynek stóp procentowych wykazuje istotny długookresowy związek z rynkiem strefy euro. Jedno- i trzymiesięczne polskie stopy procentowe wykazują związek przyczynowy ze stopami strefy euro, przy czym impulsy przebiegają od rynku euro do rynku polskiego. Jedynie w przypadku stóp sześciomiesięcznych badania wskazały na brak kointegracji. Nie stwierdzono natomiast zależności pomiędzy rynkiem polskim a rynkiem USA. Przyczyną mogą być słabsze powiązania gospodarcze, ale również rosnąca rola strefy euro na rynkach finansowych. Uzyskane wyniki sugerują dominujący kierunek przepływu impulsów cenowych od strefy euro do rynku USA. 


\title{
LITERATURA
}

Bremnes H., Gjerde O., Saettem F. (1997), A multivariate cointegration analysis of interest rates in the Eurocurrency market, ,Journal of International Money and Finance”, 16 (5), p.767-778 .

Bremnes H., Gjerde O., Saettem F. (2001), Linkages among interest rates in the United States, Germany and Norway, „Scandinavian Journal of Economics”, 103 (1), p.127-145.

Charemza W. W., Deadman D. F. (1997), Nowa ekonometria, PWE, Warszawa.

Dolado J. J., Lutkepohl H. (1996), Making Wald Tests Work for Cointegrated VAR Systems, „Econometric Review”, 15, 369-386.

Frimpong J. M., Oteng-Abayie E. F. (2008), Bivariate Causality Analysis between FDI Inflows and Economic Growth in Ghana, „International Research Journal of Finance and Economics", 15, 95-104.

Giles J. A., Mirza S. (1999), Some Pretesting Issues on Testing for Granger non-Causality, Econometrics, Working Paper EWP9914, Department of Economics, University of Victoria.

Granger C. W. J. (1969), Investigating Causal Relations by Econometric Models and Crossspectral Methods, „Econometrica”, 37, 424-438.

Granger C. W. J. (1981), Some Properties of Time Series Data and their Use in Econometric Model Specification, „Journal of Econometrics”, 16, 121-130.

Krugman P. R., Obstfeld M. (2007), Ekonomia międzynarodowa, Wydawnictwo Naukowe PWN, Warszawa.

Mills T. C., Mills A. G. (1991), The International Transmission of Bond Markets Movements, „Bulletin of Economic Research”, 43 (3), p.273-281.

Toda H. Y., Phillips P. C. (1993), Vector Autoregressions and Causality, „Econometrica”, 61, 1367-1393.

Toda H. Y., Yamamoto T. (1995), Statistical Inference in Vector Autoregressions with Possibly Integrated Processes, „Journal of Econometrics”, 66, 225-250.

Yang J., Shim J., Khan M. (2007), Casual linkages between US and Eurodollar interest rates: further evidence, „Applied Economics”, p.135-144.

Zapata H. O., Rambaldi A. N. (1997), Monte Carlo Evidence on Cointegration and Causation, „Oxford Bulletin of Economics and Statistics”, 59 (2), 285-298.

Zarra Nezhad M., Zarea R. (2007), Investigating the Causality Granger Relationship between the Rates of Interest and Inflation in Iran, „Journal of Social Science”, 3(4), 237-244.

\section{CAUSALITY ANALYSIS BETWEEN POLISH, U.S. AND EUROCURRENCY SHORT-TERM INTEREST RATES}

\begin{abstract}
A b stra ct. The main objective for this paper is to study the causal link between Polish, U.S. and Eurocurrency short-term interest rates. The paper studies the direction of causality between two variables, based on Toda and Yamamoto's Granger test which allows Granger test in an integrated system. The paper employes the one-, three- and six-month interest rates of Poland, U.S. and Eurocurrency market and tests the weekly versions of these series. The studied period is 01.01.2003-22.07.2008. The findings indicate that the eurocurrency interest rate is the Granger cause of the Polish interest rate and not vice versa. Further the eurocurrency interest rate is the Granger cause of the U.S. interest rate; there is the causal interaction between three-month rates only.

K e y w o r d s: interest rates, Granger causality, Poland, U.S., eurocurrency.
\end{abstract}

